\title{
Lightning Characteristics Based on Data from the Austrian Lightning Locating System
}

\author{
Gerhard Diendorfer, Wolfgang Schulz, and V. A. Rakov
}

\begin{abstract}
In this paper, we compare various lightning characteristics measured by the Austrian lightning locating system [Austrian Lightning Detection and Information System (ALDIS)] with those found in the literature. The latter are typically based on measurements of lightning electric fields. We show that lightning peak electric fields due to subsequent strokes measured by the ALDIS are similar to those in the literature. However, the ALDIS data do not show the usual ratio of about 2:1 between the median values of the field peaks for first and subsequent strokes. Although the flash detection efficiency of the ALDIS system in the area of investigation is estimated to be higher than $90 \%$, one of the best for such systems all over the world, the observed percentage of single-stroke flashes and the average number of strokes per flash seem to suggest that the stroke detection efficiency is appreciably less than $90 \%$. The ALDIS data indicate that larger strokes are preceded by longer interstroke intervals. The mean flash duration of $175 \mathrm{~ms}$ measured by ALDIS is similar to the typical flash duration found in the literature. Strokes with larger field peaks tend to have higher average field rates of rise. Since many lightning parameters show a large scatter for different thunderstorm days, long-term data from lightning locating systems are more representative of average lightning compared to data derived from electric field measurements typically performed during a few thunderstorms.
\end{abstract}

Index Terms - Lightning, lightning characteristics, lightning locating systems.

\section{INTRODUCTION}

$\mathbf{L}$ IGHTNING parameters are the basis for the design of lightning protection equipment and for the calculation of lightning radiated fields and their interaction with power and telecommunication lines.

There are different methods to measure lightning parameters as outlined below.

- Direct current measurements in natural lightning (e.g., Berger et al. [2]): such measurements are typically performed at tall towers or at moderate-high towers on tops of mountains, and the measured parameters may be not representative of lightning to flat ground due to longer upward connecting discharges expected from the towers. Additionally, the current wave injected at the tower top should experience reflections at ground and at any discontinuity of surge impedance along the tower.

Manuscript received December 3, 1997; revised July 31, 1998.

G. Diendorfer and W. Schulz are with the Austrian Electrotechnical Association (ÖVE), Austrian Lightning Detection and Information System (ALDIS), Vienna, Austria.

V. A. Rakov is with the Department of Electrical and Computer Engineering, University of Florida, Gainesville, FL 32611 USA.

Publisher Item Identifier S 0018-9375(98)08744-4.
- Direct current measurements in triggered lightning (e.g., Fisher et al. [8]): lightning can be artificially initiated (triggered) by launching small rockets trailing thin wires connected to ground. The leader-return stroke sequences in triggered lightning are believed to be similar to those constituting subsequent strokes of natural lightning. On the other hand, several aspects of triggered lightning suggest potential disparities between various properties of natural and triggered lightning: 1) absence of stepped leader-first return stroke sequence; 2) contamination of the lower portion of the lightning channel by the vaporized metallic wire; and 3) the fact that triggered lightning occurs under cloud conditions in which the discharge is caused to occur prematurely and may not otherwise have occurred.

- Inferences from electric and magnetic field measurements (natural and triggered lightning) (e.g., Rakov et al. [24]): Typically, only a relatively small sample of lightning data is available. In many cases, the exact stroke location is not known. Lightning peak currents are estimated using a regression equation (e.g., Rakov et al.[22]; Idone et al. [9]) relating the measured lightning peak fields and the lightning peak currents or a relation based on the socalled transmission line return-stroke model (e.g., Willet et al. [30]). Field measurements are usually performed at a single station.

- Lightning locating systems (e.g., Orville et al. [18]): The output of modern multiple-station lightning locating systems includes, besides lightning coordinates, estimates of lightning peak current and number of strokes per flash (multiplicity). When data from lightning locating systems are used, very often too little attention is paid to one of the most important performance parameters of the system, the so-called detection efficiency (DE). Most of the published lightning parameters based on data from locating systems are presented without any comments on systems DE. In many papers, important system parameters such as threshold levels of the sensors and network configuration, which both strongly influence DE and which could be used for its rough estimation, are not reported. Further, current peaks are determined from lightning peak fields measured by the system using a semi-empirical equation. The peak field is the mean value of the range normalized peak fields reported by multiple stations. It is not clear if a relation between peak fields and peak currents determined in a certain region is also valid for other regions with different ground conductivity 


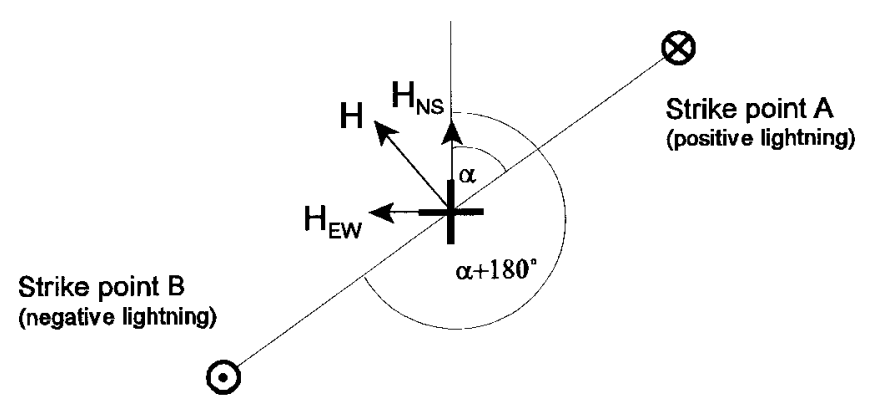

Fig. 1. Determination of the angle to the lightning strike point.

and, therefore, different field propagation effects. Signal range normalization assuming a $1 / R$ distance dependency is exact only for propagation over ground of infinite conductivity. The signal can be normalized also in other ways (e.g., Idone et al. [9]), using a more sophisticated propagation model or experimental approach to account for propagation effects. One of the major advantages of lightning locating systems is that the measurements are usually available for entire year or even for several years so that the sample size is large and different seasons and types of thunderstorms are included in the data base.

In this paper, we consider only those lightning parameters we can extract from the lightning data base obtained using the Austrian lightning locating system [Austrian Lightning Detection and Information System (ALDIS)]. Additionally, comparison is done only with data for natural lightning (tower measurements or field measurements) and not with data for triggered lightning.

\section{Methodology}

The lightning locating system (described in Section III) used for this study is manufactured by Lightning Location and Protection, Inc. (LLP), a subsidiary of Global Atmospherics, Inc. (GAI), and is probably the most widely used for lightning detection. The system consists of several sensors and a processing unit. In general, a minimum of two sensors are required to find the location. Each sensor determines: 1) the angle to the lightning stroke and 2) the time of each detected stroke using a global positioning system (GPS) synchronized clock with a timing error of less than $300 \mathrm{~ns}$. From these sensor data the central processing unit, the so-called position analyzer (PA), calculates the strike point location. For a comprehensive description of lightning locating technique, see Krider et al. [13] and Cummins et al. [5].

Each sensor has two wide-band crossed magnetic loop antennas to measure the north-south and the east-west components of the magnetic field (Fig. 1).

The angle $\alpha$ (azimuth) to the ground strike location is calculated using the ratio of signals from the two crossed-loop antennas

$$
\tan \alpha=\frac{H_{N S}}{H_{E W}} .
$$

A positive stroke in location $\mathrm{A}$ and a negative stroke in location B in Fig. 1 are indistinguishable in terms of the magnetic field at the antenna site. Therefore, in addition to the magnetic field $H$, electric field $E$ is measured to eliminate this $180^{\circ}$ ambiguity. The direction finders (DF's) are designed to determine the direction at the initial peak of the signal, generally occurring within some microseconds of the return stroke initiation at ground level. Considering an average return-stroke velocity of $100 \mathrm{~m} / \mu \mathrm{s}$ and a typical field rise time of some microseconds, the peak field is already formed, when the return-stroke channel has extended to only some hundred meters above ground. It is assumed that this lower portion of the lightning channel is essentially straight and vertical. Uman et al. [29] estimated angle errors due to nonvertical channels for lightning beyond $10 \mathrm{~km}$ to be less than one degree. Of course, this type of error decreases with increasing distance.

The bandwidth of the sensor (DF) is in the range from 1-350 $\mathrm{kHz}$, which is sufficient to preserve the main features of the field waveform. The DF separates signals due to cloud-toground (CG) return strokes from any other signals (intercloud and intracloud lightning, local noise, etc.) by applying the so-called "waveform discrimination algorithm" discussed by Krider et al. [14]. Waveform discrimination is based on the use of several criteria, which field waveforms have to satisfy. Not all the details are available about these criteria because they are, to a certain degree, confidential to the manufacturer. Soerensen [26] and Johannsdottir [11] have reviewed the presently existing knowledge in this area.

Each signal exceeding the sensor threshold is examined for compliance with the waveform criteria. The DF has a dead time of about 3-4 ms for analyzing the signal accepted as CG return-stroke pulse and about $300 \mu$ s for the signal not meeting the waveform criteria.

For field waveshapes that satisfy the waveform criteria during dead time, angle of field incidence, time, and signal strength are determined by the DF and sent to the advanced position analyzer (APA). Data from different DF's are grouped by the APA based on angle and time where a time window of a few milliseconds is applied. The flash location is calculated by different algorithms, depending on the number of reporting DF's. In the Austrian system, more than $98 \%$ of all locations are calculated with an optimization algorithm. Other possibilities to calculate the flash position as a function of available sensor information are described comprehensively in Schulz [25].

\section{The Austrian Lightning Locating System ALDIS}

At the end of 1991, a lightning detection system based on magnetic direction finding was first installed in Austria (Diendorfer et al. [6]) and upgraded to the so-called IMPACT technology in 1994. The IMPACT (IMProved ACcuracy from Combined Technology) technology combines the advantages of a magnetic direction finding system and a time of arrival system. Time synchronization by GPS signals keeps the absolute timing error between sensors smaller than $300 \mathrm{~ns}$. Each IMPACT DF reports angle, absolute time, amplitude (measured with respect to zero level), polarity, risetime, and pulse width for each individual stroke of a multistroke flash. Both the risetime $T_{r}$ and pulse width $T_{w}$ are measured above the threshold level, as illustrated in Fig. 2. 


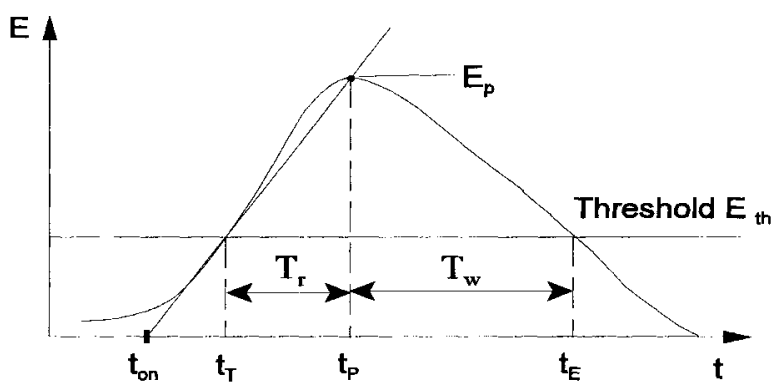

Fig. 2. Pulse risetime $T_{r}=\left(t_{P}-t_{T}\right)$ and pulse width $T_{W}=\left(t_{E}-t_{P}\right)$ as reported by the IMPACT sensor.

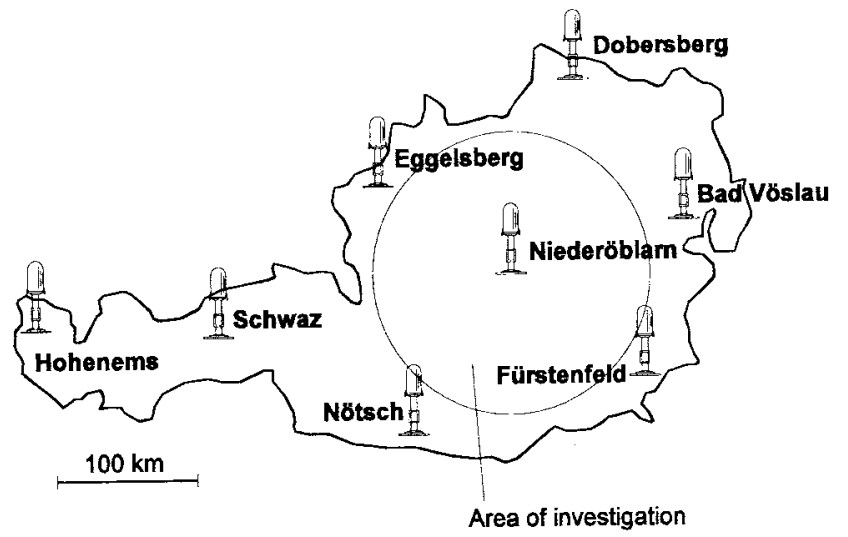

Fig. 3. Direction finder locations in Austria.

The data analyzed in this paper were recorded by the IMPACT system in Austria and therefore the configuration of this network is given in more details below.

The ALDIS is a high-gain network of eight direction finders with a mean baseline between sensors of about $120 \mathrm{~km}$ (see Fig. 3). Six of these direction finders are installed at small airports, and the remaining two are located on private property. The sites in Austria were selected very carefully to achieve a measurement of the lightning electromagnetic fields with minimal distortion by local objects. Note from Fig. 2 that the risetime $T_{r}$ and pulse width $T_{w}$ reported by the sensor are affected by the signal amplitude $E_{p}$ relative to the threshold level $E_{\mathrm{th}}$. We can estimate the zero-to-peak risetime $T_{\text {rise }}=$ $\left(t_{P}-t_{\mathrm{ON}}\right)$ of the pulse from

$$
T_{\text {rise }}=T_{r} \cdot \frac{E_{P}}{E_{P}-E_{\text {th }}} .
$$

The low electromagnetic noise level at the carefully selected sensor sites allowed us to reduce the threshold level of all the sensors from $100 \mathrm{mV}$ (manufacturer's standard setting) to 70 $\mathrm{mV}$ for negative flashes in summer. Lowering the threshold of the sensors improves the detection efficiency of the network and lowers the minimum peak signal the system is able to detect. Threshold setting of $70 \mathrm{mV}$ corresponds to a minimum electric field of $0.36 \mathrm{~V} / \mathrm{m}$. A reduction of threshold also causes an increase of the area covered by the network and, therefore, during periods of very high lightning activity, some flashes can be missed (deferred flashes) due to the limited processing capability of the advanced position analyzer (APA). Therefore,
TABLE I

WaVeform Criteria Used in the Austrian Network for Both Positive and Negative Lightning Strokes

\begin{tabular}{c|c|c}
\hline & minimum & maximum \\
\hline E/B ratio & 0.2 & 3.0 \\
\hline pulse rise time & 0 & $24 \mu \mathrm{s}$ \\
\hline pulse width & $6 \mu \mathrm{s}$ & $31 \mu \mathrm{s}$ \\
\hline
\end{tabular}

further decrease of threshold level in summer is not justified. During winter time, when lightning activity in Central Europe is a generally low, the threshold is further lowered to $50 \mathrm{mV}$. For positive flashes, threshold is preset by the manufacturer at $350 \mathrm{mV}(1.8 \mathrm{~V} / \mathrm{m})$ and is not adjustable by the operator. Only negative flashes are considered in this study.

Further, in the Austrian network the minimum signal width criterion was changed from the standard setting of $11 \mu \mathrm{s}$ toa value of $6 \mu \mathrm{s}$. The relaxation of the width criterion was prompted by the observations of CG-strokes with a pulse width smaller than $11 \mu \mathrm{s}$ (Ishii et al. [10]), particularly during winter thunderstorms. Thus, any signal wider than $6 \mu \mathrm{s}$ (above threshold level) is identified as CG stroke provided that this signal meets all other waveform criteria some of which are given in Table I. Most of the signals from cloud lightning are expected to fail this width criterion.

For pure radiation electromagnetic fields, the $E / B$ ratio where $B$ is the magnetic flux density, is equal to the speed of light. The $E / B$ ratio based on the values of $E$ and $B$ measured by the sensor depends on the gains of the electric and magnetic field antennas. The magnetic field gain is fairly constant, but the electric field gain depends on the installation (e.g., due to field enhancement for roof mounted sensors).

The position analyzer (APA 280-T) installed in Austria is the so-called single processor APA. The limited processing capability of the single processor APA requires operation in all stroke reporting (ASR) mode for real-time lightning. In the ASR mode, signals detected by individual sensors (DF's) are assigned to the same stroke if they: 1) are of the same polarity and 2) occur within a specified time window set at $3 \mathrm{~ms}$ in the Austrian network. Then strokes are grouped into flashes based on their azimuths with respect to previous strokes as shown in Fig. 4. Location of the stroke detected by the largest number of sensors is assigned to all strokes in the flash, assuming that this will provide the most accurate stroke location.

Estimation of the lightning peak current for this study is based on a range-normalized field signal $S_{n}$ and

$$
i_{p}=0.23 S_{n}
$$

where $i_{p}$ is the lightning peak current in kA and $S_{n}$ is the mean of the signal strengths from the DF's participating in the location in LLP-units range-normalized to $100 \mathrm{~km}$. The coefficient 0.23 in (3) is the standard setting proposed by the manufacturer for a high-gain network. Up until now the most reliable relationship between $i_{p}$ and $S_{n}$ was obtained using Florida triggered-lightning data by Idone et al. [9]. A plot of measured peak currents versus mean normalized signal strength $S_{n}$ (in LLP units) for 56 triggered strokes was fitted 


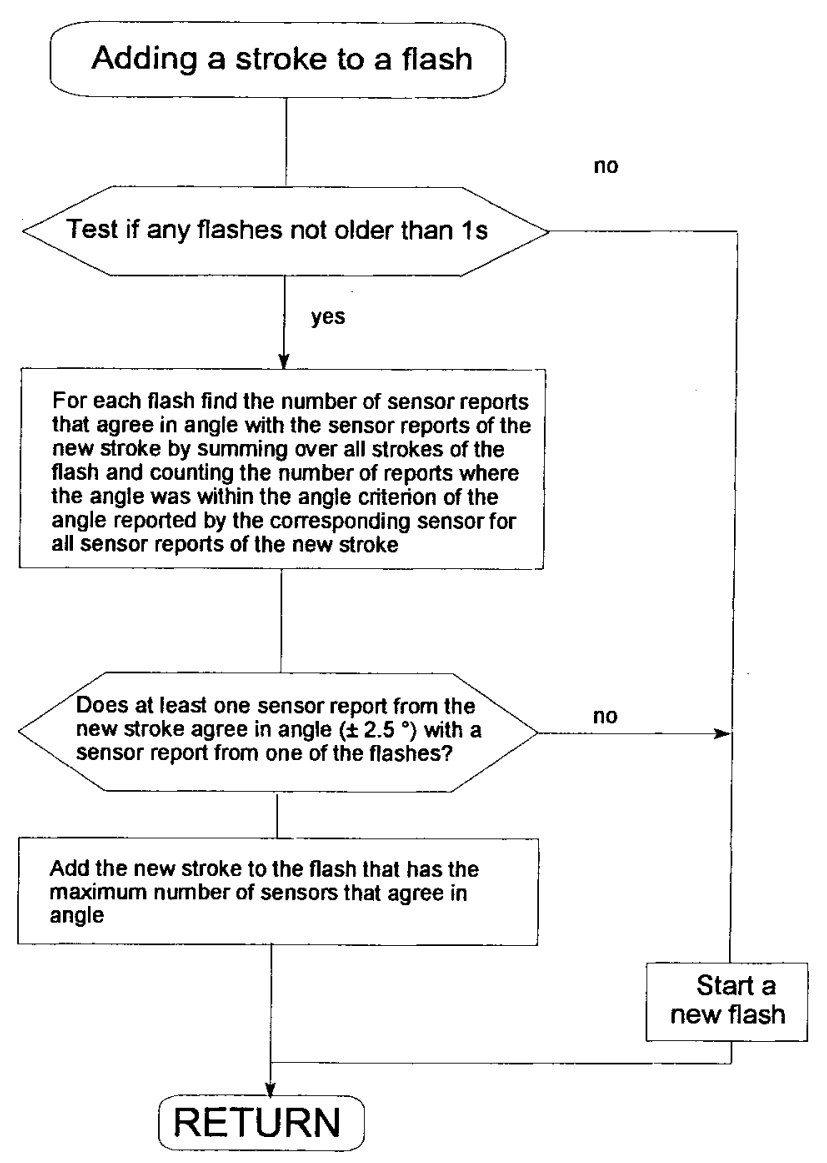

Fig. 4. Flowchart of flash grouping algorithm.

by the regression equation

$$
i_{p}=4.2+0.17 S_{n}
$$

with a correlation coefficient $r=0.88$ and a standard deviation $\sigma=4.6 \mathrm{kA}$. It is important to note that this correlation is not based on any return-stroke model. The only assumption made is sufficient similarity of strokes in triggered lightning and first and subsequent strokes in natural lightning in terms of the relation between peak currents and peak fields. Recently performed current measurements for natural lightning hitting catenary wires at the Kennedy Space Center support this assumption (Cummins, 1997, personal communications).

A comparison of (3) and (4) shows that the setting used by ALDIS gives a $25 \%$ higher peak current compared to the equation of Idone et al. [9], when the intercept of $4.2 \mathrm{kA}$ is neglected.

\section{Lightning PARAMETERS BASEd ON DATA From ALDIS}

\section{A. Dataset}

All lightning parameters analyzed in this paper are from flashes located in 1996 in a circular area of $100 \mathrm{~km}$ radius around DF4 $\left(14.009^{\circ}\right.$ E, $\left.47.480^{\circ} \mathrm{N}\right)$, shown in Fig. 3. This limited area was chosen because it is characterized by presumably the best detection efficiency within the Austrian lightning locating system. A flash detection efficiency of better than $90 \%$ is estimated for that area. Due to the relatively short baselines between sensors ranging from $120-150 \mathrm{~km}$ the location system
TABLE II

Peak Current Distribution Obtained by Berger et al. [2]

\begin{tabular}{c|c|c|c|c}
\cline { 2 - 5 } & Unit & $95 \%$ & $50 \%$ & $5 \%$ \\
\hline negative first strokes & $\mathrm{kA}$ & 14 & 30 & 80 \\
\hline negative subsequent strokes & $\mathrm{KA}$ & 4.6 & 12 & 30 \\
\hline
\end{tabular}

is able to detect strokes of small peak amplitudes down to 2 $\mathrm{kA}$ as estimated from (3). The examined area around DF4 is mainly mountainous with mountain tops up to altitudes of 3000 $\mathrm{m}$ and presumably of low-ground conductivity. Analyzing data from the entire network instead of the selected area would result in a significant bias in the lightning parameters. Outside the network, as the distance increases only strokes of higher peak current are detected, resulting in an increase of the mean value of the peak current distribution (Diendorfer et al. [7]. Analyzed here are data over one full year including all different types of thunderstorms, e.g., air-mass (convective) and frontal, occurring in Austria.

In 1996, the locating system detected more than 20 flashes per day on 62 days in the selected region. We use only these days with more than 20 flashes per day for the analyzes involving thunderstorm days, although on several other days a few flashes have been detected inside the selected area. Inclusion of these latter data in the analyses related to thunderstorm days would result in unrealistic conclusions.

It is important to note, that the detection efficiency for a flash is higher than for a stroke. For a multistroke flash, it is sufficient to detect at least one of the strokes by a minimum of two DF's to have a flash detection. To detect all strokes, each individual stroke requires a minimum of two reporting DF's to obtain a solution. Clearly, the probability of stroke detection is lower than the probability of flash detection, with smaller strokes being preferentially missed.

The number of strokes per flash, termed multiplicity, reported by the APA in ASR mode is the largest of: 1) the number of strokes simultaneously recorded by two or more sensors and 2) the number of strokes reported by any one of the sensors. Thus, multiplicity includes not only located strokes, but also strokes detected by only one DF.

All the following analyses are limited to negative flashes. The selected set of data has a total of 46420 flashes with 126955 strokes with 28758 (about 25\%) strokes being detected by a single DF. The average number of strokes per flash (multiplicity) is 2.7 .

\section{B. Lightning Peak Field and Peak Current}

Lightning peak current is one of the most important lightning parameters. Almost all of the national and international standards on lightning protection are based on lightning current measurements in Switzerland (Berger et al. [2]). These measurements were performed on two instrumented towers on top of the mountain Monte San Salvatore. Minimum peak current in Berger's data is $2 \mathrm{kA}$. Lightning peak currents are lognormally distributed and usually described by either a median value and the standard deviation or by the 5,50, and 95\% values (see Table II). 
TABLE III

Electric Field Peak Normalized to 100 kM Versus Stroke Order Measured by AldiS and Rakov and Uman [21]

\begin{tabular}{|c|c|c|c|c|c|c|}
\hline \multirow{2}{*}{$\begin{array}{l}\text { Stroke } \\
\text { order }\end{array}$} & \multicolumn{6}{|c|}{ Rakov \& Uman [1990] } \\
\hline & $\begin{array}{c}\text { sample } \\
\text { size }\end{array}$ & GM & SD of $\log _{10}(x)$ & $95 \%$ & $50 \%$ & $5 \%$ \\
\hline- & - & $\mathrm{V} / \mathrm{m}$ & - & $\mathrm{V} / \mathrm{m}$ & $\mathrm{V} / \mathrm{m}$ & $\mathrm{V} / \mathrm{m}$ \\
\hline 1 & 76 & 5.9 & 0.22 & 2.5 & 5.9 & 13.6 \\
\hline 2 & 63 & 3.4 & 0.29 & 1.1 & 3.4 & 10.2 \\
\hline 3 & 51 & 3.7 & 0.29 & 1.2 & 3.7 & 11.1 \\
\hline 4 & 41 & 2.9 & 0.29 & 1 & 2.9 & 8.7 \\
\hline $5-7$ & 62 & 2.3 & 0.28 & 0.8 & 2.3 & 6.6 \\
\hline $8-18$ & 53 & 2.4 & 0.3 & 0.8 & 2.4 & 7.5 \\
\hline $\begin{array}{c}\text { all } \\
\text { subsequent } \\
\text { strokes } \\
\end{array}$ & 270 & 2.9 & 0.3 & 0.9 & 2.9 & 9 \\
\hline Stroke & \multicolumn{6}{|c|}{$A L D \mid S$} \\
\hline order & $\begin{array}{c}\text { sample } \\
\text { size }\end{array}$ & GM & SD of $\log _{10}(x)$ & $95 \%$ & $50 \%$ & $5 \%$ \\
\hline- & - & $\mathrm{V} / \mathrm{m}$ & - & $\mathrm{V} / \mathrm{m}$ & $\mathrm{V} / \mathrm{m}$ & $\mathrm{V} / \mathrm{m}$ \\
\hline 1 & 43133 & 2.1 & 0.34 & 0.6 & 2.1 & 7.6 \\
\hline 2 & 19013 & 2.2 & 0.24 & 0.9 & 2.2 & 5.5 \\
\hline 3 & 11783 & 2.2 & 0.25 & 0.9 & 2.2 & 5.7 \\
\hline 4 & 7761 & 2.1 & 0.26 & 0.8 & 2.1 & 5.6 \\
\hline 5 & 5199 & 2 & 0.28 & 0.7 & 2 & 5.8 \\
\hline 6 & 3572 & 1.9 & 0.26 & 0.7 & 1.9 & 5.1 \\
\hline 7 & 2424 & 1.8 & 0.26 & 0.7 & 1.8 & 4.8 \\
\hline 8 & 1682 & 1.8 & 0.26 & 0.7 & 1.8 & 4.8 \\
\hline 9 & 1194 & 1.7 & 0.26 & 0.6 & 1.7 & 4.6 \\
\hline 10 & 815 & 1.7 & 0.24 & 0.7 & 1.7 & 4.2 \\
\hline $\begin{array}{c}\text { all } \\
\text { subsequent } \\
\text { strokes }\end{array}$ & 53443 & 2.1 & 0.25 & 0.8 & 2.1 & 5.4 \\
\hline
\end{tabular}

TABLE IV

EXPRESSIONS FOR THE CONVERSION OF PEAK Electric Fields (at $100 \mathrm{~km}$ ) to Peak Currents

\begin{tabular}{l|c|c}
\cline { 2 - 3 } & $\begin{array}{c}\text { Equation } \\
\mathrm{I} \text { in }[\mathrm{KA}], \mathrm{E}_{100} \text { in }[\mathrm{V} / \mathrm{m}]\end{array}$ & $\mathrm{I}[\mathrm{kA}]$ for $\mathrm{E}_{100}=6 \mathrm{~V} / \mathrm{m}$ \\
\hline $\begin{array}{l}\text { GAI default calibration } \\
\text { (applied to the ALDIS data) }\end{array}$ & $\mathrm{I}=-5.12^{\star} \mathrm{E}_{100}$ & -30.7 \\
\hline Rakov et al. [1992a] & $\mathrm{I}=1.5-3.7^{\star} \mathrm{E}_{100}$ & -20.7 \\
\hline Idone et al. [1993] & $\mathrm{I}=-4.2-3.81^{\star} \mathrm{E}_{100}$ & -27.1 \\
\hline
\end{tabular}

Estimation of the lightning peak current from electric field measurements in Florida was done by Rakov and Uman [21] (see Table III) and Rakov et al. [22], with the current/field equation (Rakov et al. [22]) based on triggered-lightning data of Willett et al. [30], given in Table IV.
The Austrian lightning locating system ALDIS estimates the peak current from the measured peak magnetic field. In contrast with the single-station field measurements by Rakov and Uman [21], the field peak in this study is the mean of the range-normalized signal strengths of all reporting sensors (up to eight). Table III shows a comparison of the peak electric field distributions measured by ALDIS and by Rakov and Uman [21] as a function of stroke order. To compute the 5, 50, and 95\%values for the data from Rakov and Uman [21], we assume a lognormal distribution for the peak electric field and use their reported geometric mean and standard deviation. Therefore, the geometric mean (GM) and the median (50\% value) in Table III are identical.

A graph of the results in Table III that illustrates the similarities and differences between the two data sets is shown in Fig. 5. 


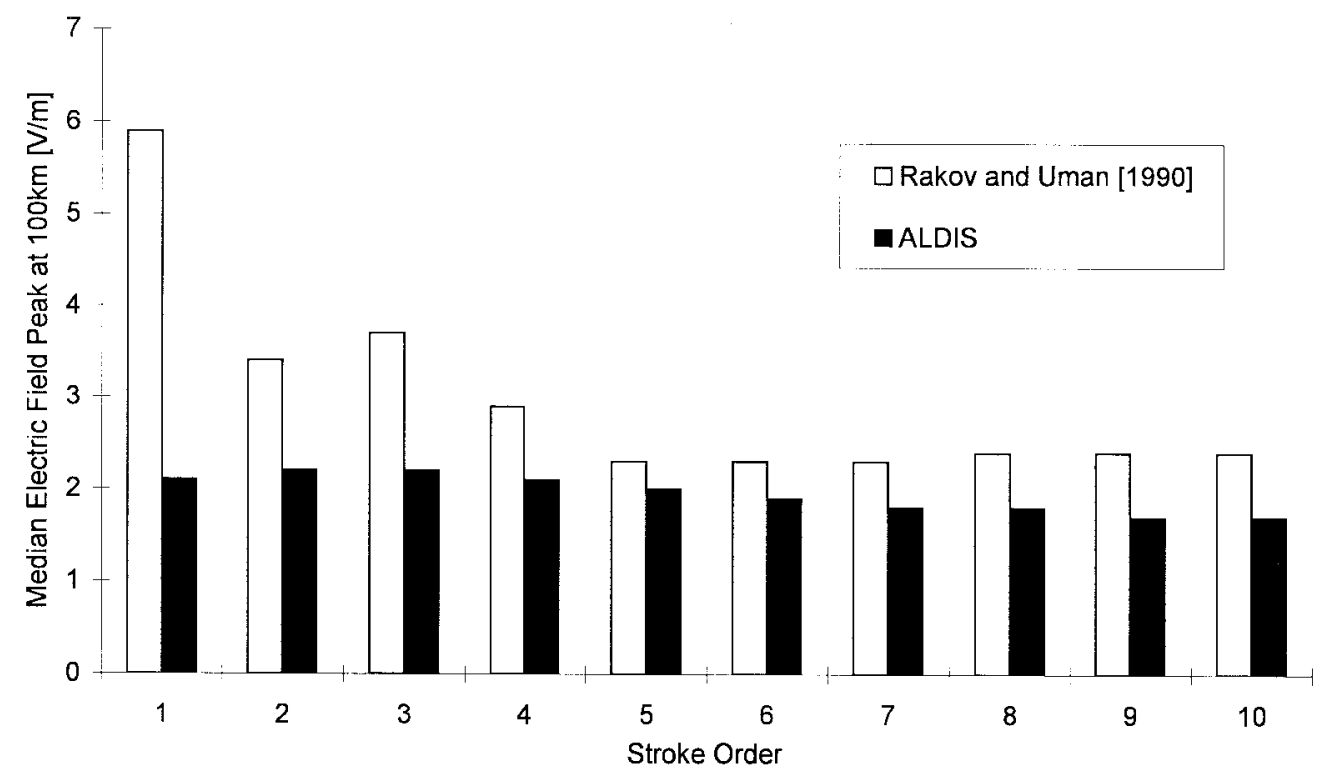

Fig. 5. Median initial electric field peak normalized to $100 \mathrm{~km}$ versus stroke order.

Clearly, the data from the lightning locating system do not show the usual ratio of about $2: 1$ between the median values of the electric field peaks for first and subsequent strokes. One of the reasons for this could be the lightning locating system is missing a significant number of first strokes. We tested this hypothesis using independent electric field measurements in Austria that were time correlated with ALDIS reports (Maier et al. [16]). These independent field measurements revealed that in about $10 \%$ of all flashes, the location system misses the first stroke and misidentifies the second stroke as the first one. This percentage seems to be too low to explain the significant differences between the median electric field peaks for first strokes from measurements by ALDIS and those of Rakov and Uman [21]. Also, the independent electric field measurements taken separately do not show the 2:1 ratio between peak fields for first and subsequent strokes. If we assume that the lower first-stroke peaks are due to cloud discharges which were erroneously accepted as CG strokes and that cloud discharges are mostly detected as single-pulse events, we can try to eliminate the misidentified events considering only multiple-stroke flashes. To test this hypothesis, we calculated the median peak field for first strokes in multiple-stroke flashes only (excluding single-stroke flashes). The resulting value of $2.5 \mathrm{~V} / \mathrm{m}$ is only about $20 \%$ greater than $2.1 \mathrm{~V} / \mathrm{m}$ for all first strokes (see Table III) and, therefore, we can rule out the hypothesis regarding a significant influence of cloud discharges (provided they are indeed detected as single-pulse events). Independent of the number of strokes in a flash, for about $10 \%$ of the flashes in our data set the first stroke was detected only by a single DF. Those flashes were not included in the peak field analysis since no range-normalized signal peak could be determined.

In order to compare values of peak current from the lightning locating system (Fig. 5) with the peak current values determined by Berger et al. [2] (Table II) a calibration function has to be applied to convert peak fields to peak currents.
TABLE V

Multistroke Flashes with at Least One Subsequent Stroke-Peak Greater Than First Stroke Peak

\begin{tabular}{l|c}
\hline Thottappillil et al. [1992] & $33 \%$ \\
\hline Cooray and Perez [1994] & $24 \%$ \\
\hline Cooray and Jayaratne [1994] & $35 \%$ \\
\hline ALDIS & $51 \%$ \\
\hline
\end{tabular}

The DF measures peak field and reports this peak to the position analyzer in arbitrary units called LLP units. The correspondence between the LLP units and the electric field is given by the manufacturer in the form

$$
1158 \text { LLP-Units }=52 \mathrm{~V} / \mathrm{m} \text {. }
$$

In Table IV we summarize three commonly used equations for the conversion of lightning electric fields to lightning currents. For comparison we have written all these functions in a form where range $(100 \mathrm{~km})$-normalized electric field $E_{100}$ is used as an input by applying the correspondence given in (5). The traditional atmospheric electricity sign convention is assumed where a positive field corresponds to a negative current.

For a range normalized peak electric field of $6 \mathrm{~V} / \mathrm{m}$ the three equations result in a peak current in the range of 20-30 kA. Differences in the calculated peak current vary as a function of $E_{100}$ due to the different intercepts and slopes of the three equations.

Using the GAI calibration we find that the median electric field of $2.1 \mathrm{~V} / \mathrm{m}$ for subsequent strokes in Table III corresponds to a median peak current of about $11 \mathrm{kA}$. This is similar to the $12 \mathrm{kA}$ reported by Berger et al. [2] and about $10 \mathrm{kA}$ found by Rakov et al. [22]. 


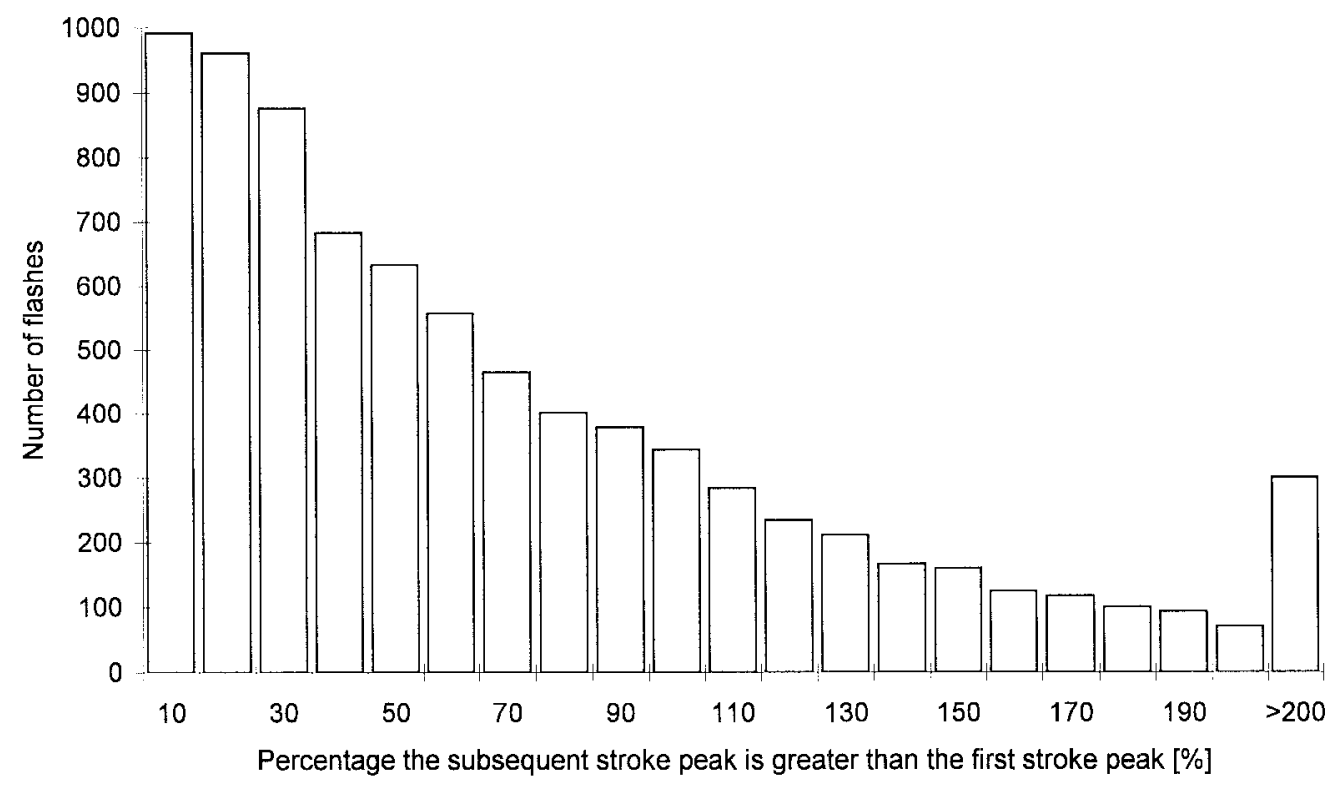

Fig. 6. Frequency distribution of the percentage by which maximum subsequent stroke amplitude exceeds the corresponding first stroke amplitude. One hundred percent means that the largest subsequent stroke is a factor of two greater than the first stroke in the flash.

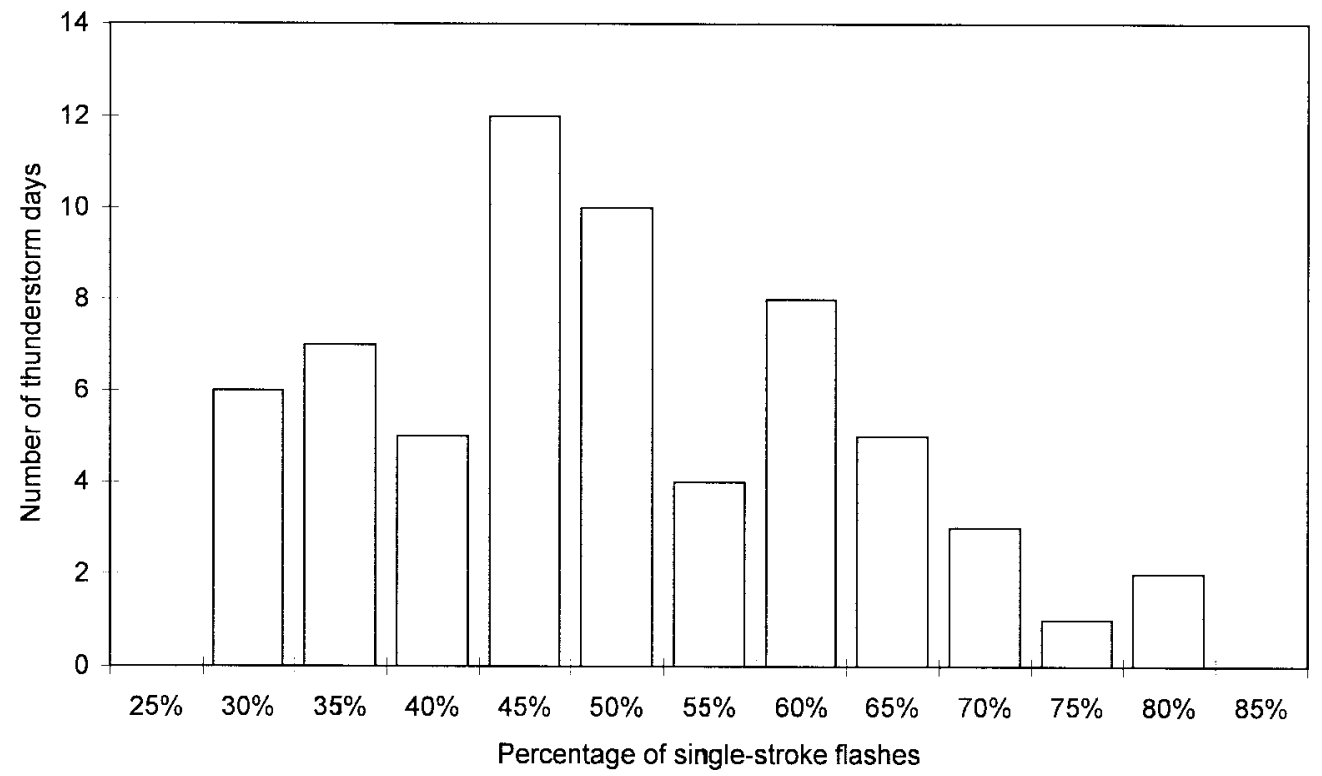

Fig. 7. Number of thunderstorm days with different percentage of single-stroke flashes.

\section{Subsequent Stroke Peak Fields Greater Than the First Stroke Peak Fields}

The 1996 ALDIS data set examined in this section includes 15905 flashes with more than one stroke. This number of flashes is lower than the number of flashes used in Section IVB because here we only included flashes with first strokes detected by at least two DF's in order to be able to examine their range-normalized peak fields. $51 \%(N=8149)$ of the total number of flashes with more than one stroke contained at least one subsequent stroke with a peak greater than the peak of the first stroke. Comparison with published results of similar investigations is given in Table V.
To quantify how much the peak of one of the subsequent strokes exceeds the peak of the first stroke in these flashes, we calculated the ratio of the maximum subsequent stroke peak field to the peak field of the first stroke.

Fig. 6 shows the frequency distribution of the percentage by which maximum subsequent stroke amplitude exceeds the corresponding first stroke amplitude. The median value for the distribution in Fig. 6 is 51\%. That means $50 \%$ of the flashes with a subsequent stroke with a peak greater than the peak of the first stroke have a peak amplitude which is 1.51 times higher than the first stroke. The numerical equivalence of this median value $(51 \%)$ and the percentage given in Table $\mathrm{V}$ is 


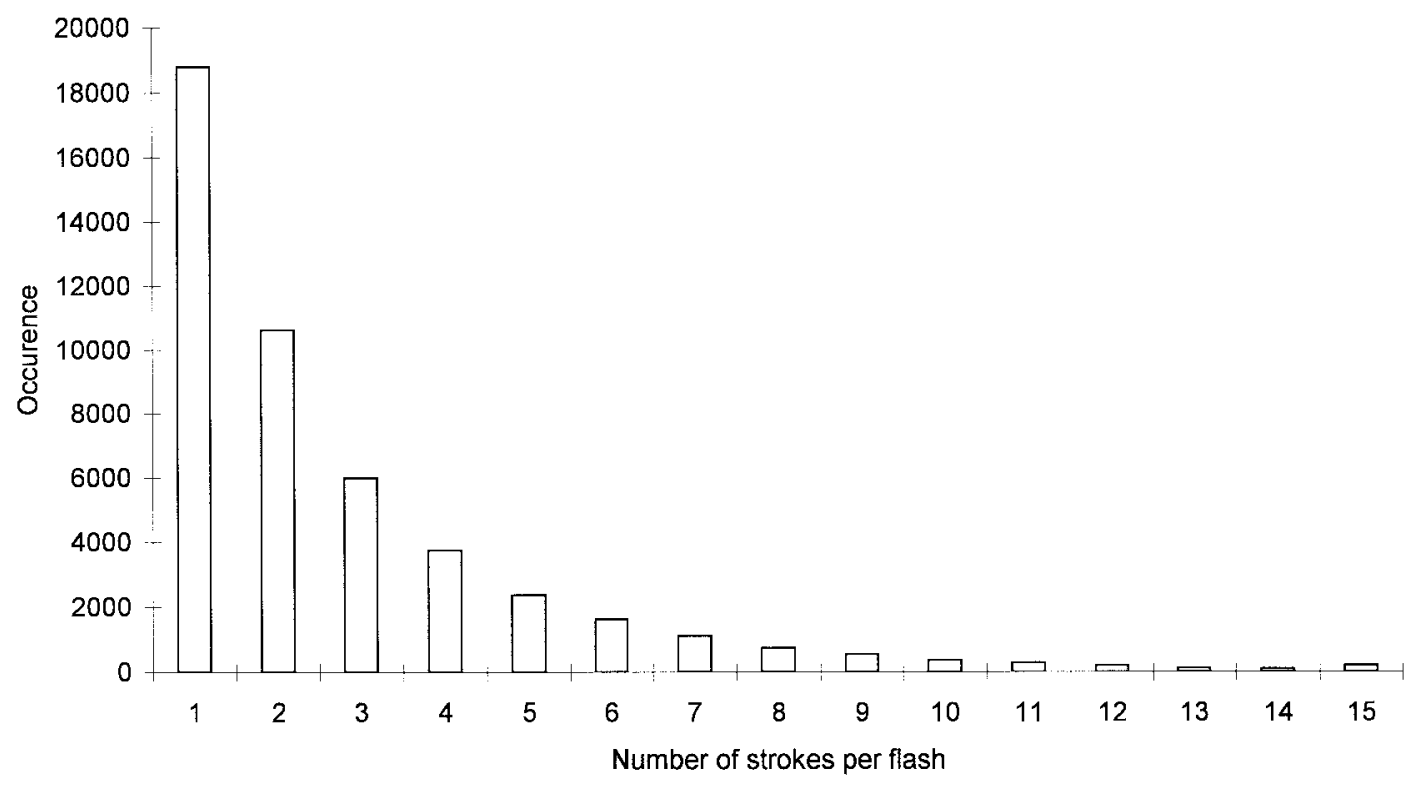

Fig. 8. Distribution of the number of strokes per flash.

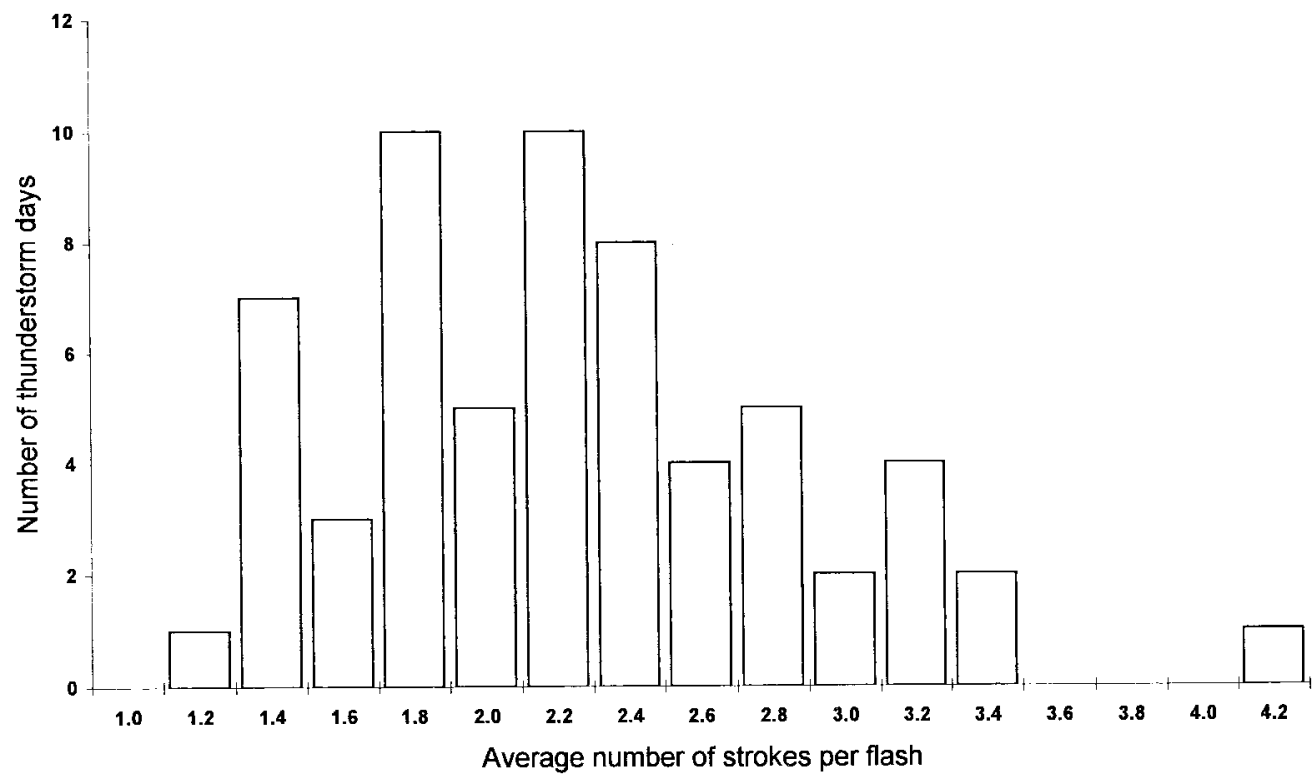

Fig. 9. Number of thunderstorm days (more than 20 flashes per day) with different average number of strokes per flash.

merely a coincidence. All flashes with the largest subsequent stroke peak more than three times greater than the first stroke peak are lumped in the rightmost bar of Fig. 6. Some of those flashes could be the result of a missed first stroke due to limited detection efficiency and misidentifying a small subsequent stroke as the first stroke or the misidentification of an initial breakdown pulse as the first stroke.

\section{Percentage of Single-Stroke Flashes}

Forty percent of all the flashes detected by ALDIS in 1996 were single-stroke flashes. Different percentages of singlestroke flashes are reported in the literature (e.g., Rakov et al. [24] 17\%, Cooray and Perez [3] 18\%, Cooray and Jayaratne [4] 21\%, Kitagawa et al. [12] 14\%, Anderson and Erikson
[1] 45\%). Rakov et al. [24] argue that their data and those of Kitagawa et al. [12] are superior to data of Anderson and Erikson [1] in terms of reliability of stroke count.

We have additionally determined the percentage of singlestroke flashes for each of the 62 thunderstorm days with more than 20 flashes per day in 1996 and the resulting histogram is shown in Fig. 7.

As seen in Fig. 7, the percentage of single-stroke flashes varies significantly from storm to storm (from 30 to $80 \%$ with a mean of $40 \%$ ) and probably depends on season, type of thunderstorm, etc. The minimum value of $30 \%$ measured by ALDIS is still higher than the $17 \%$ of Rakov et al. [24] or the $14 \%$ of Kitagawa et al. [12]. A reason for this could be the limited stroke detection efficiency of the detection system that causes missing of smaller strokes. 
TABLE VI

Preceding Interstroke Interval Versus Stroke Order (RAKov et al. [24])

\begin{tabular}{c|c|c|c}
\hline Stroke order & 2 & $2-4$ & $5-18$ \\
\hline Geometric mean [ms] & $56(63)$ & $66(155)$ & $54(115)$ \\
\hline
\end{tabular}

TABLE VII

PRECEDING INTERSTROKE INTERVALS REPORTED By ALDIS

\begin{tabular}{c|c|c|c|c}
\hline Stroke order & 2 & 3 & 4 & 5 \\
\hline Geometric mean [ms] & 58 & 56 & 56 & 58 \\
\hline
\end{tabular}

\section{E. Average Number of Strokes Per Flash}

Rakov et al. [24] reported the average number of strokes per flash to be 4.6 in Florida. From ALDIS data the average number of strokes per flash is 2.7. The distribution of the number of strokes per flash is shown in Fig. 8. The IMPACT sensors are limited to a maximum of 15 strokes per flash. Therefore, in Fig. 8, the bar (for stroke 15) represents all flashes with 15 or more strokes. This also explains the increase in the histogram from 86 flashes with 14 strokes to 188 flashes with 15 strokes. Only a very small percentage of flashes has more than 15 strokes and, therefore, this sensor limitation should not cause an appreciable bias in the data.

Analyzing the individual thunderstorm days shows a significant variability of the average number of strokes per flash in the range from 1.2 to 4.2 as depicted in Fig. 9 . probably due to dependency on season (winter/summer) and thunderstorm type (convective/frontal). The limited stroke detection efficiency of the location system could also cause some bias toward lower values.

\section{F. Interstroke Intervals}

For a sample of 270 subsequent strokes, Rakov et al. [24] determined that the geometric mean interstroke interval is 60 ms. They also reported a dependency on stroke order, as shown in Table VI. Berger et al. [2] gives a geometric mean for the interstroke interval of $33 \mathrm{~ms}(N=133)$.

For the data set used in this study we calculated a geometric mean of $56 \mathrm{~ms}$ for all strokes regardless of stroke order. The interstroke interval as a function of stroke order is given in Table VII. In this table all interstroke intervals up to $1 \mathrm{~s}$ are included (see also explanation of stroke to flash grouping algorithm in Section IV-A).

The interstroke intervals of the ALDIS data (Table VII) are similar to those observed by Rakov et al. [24]. No significant dependency on stroke order was found in the ALDIS data.

Channel conditions characterized by interstroke interval and number of preceding strokes presumably influence the development of the dart leader and the charge required to drive a new leader (Rakov et al. [4]. We tested this hypothesis by calculating the mean of range-normalized peak electric field as a function of the preceding interstroke interval.

For interstroke intervals from 3 to $100 \mathrm{~ms}$ with an increment of $1 \mathrm{~ms}$, we have calculated the mean of the peak field. The $3 \mathrm{~ms}$ dead time of the sensor (when it is processing a stroke) determines the minimum interstroke interval that can be measured by the locating system. For interstroke intervals

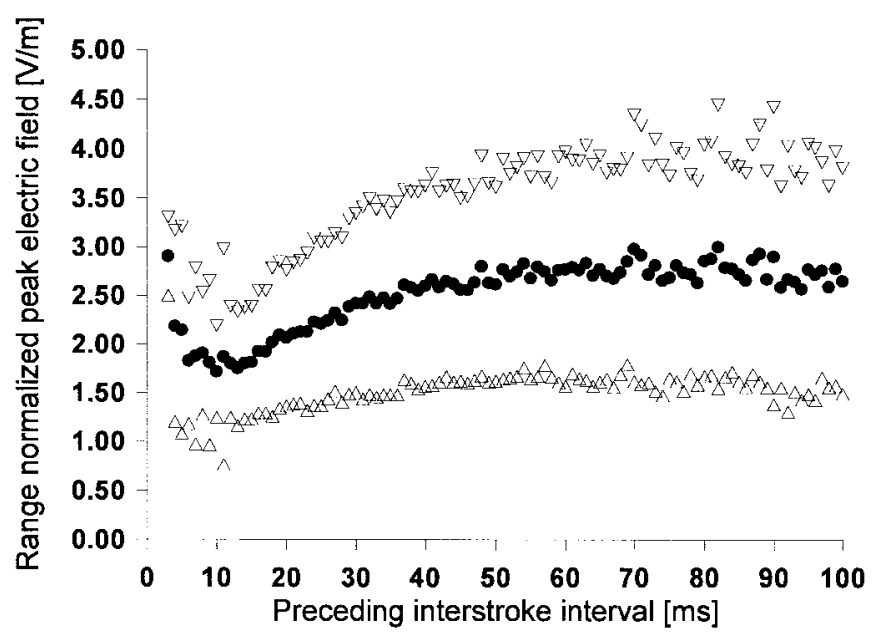

Fig. 10. Mean-peak electric field versus preceding interstroke interval (• mean values, $\Delta, \nabla \cdots \pm$ standard deviation).

TABLE VIII

Flash Duration [ms] Measured by Berger et al. [2] AND By ALDIS

\begin{tabular}{l|c|c|c}
\cline { 2 - 4 } \multicolumn{1}{c|}{} & $95 \%$ & $50 \%$ & $5 \%$ \\
\hline Berger et al. [1975] & 31 & 180 & 900 \\
\hline ALDIS & 23 & 175 & 725 \\
\hline
\end{tabular}

ranging from 10 to $60 \mathrm{~ms}$, Fig. 10 shows an increase of the mean range-normalized peak field with an increase of preceding interstroke interval.

The triangles $(\Delta, \nabla)$ below and above the calculated mean values $(\bullet)$ of the range- normalized peak fields represent the plus/minus standard deviation which is, on average, $0.8 \mathrm{~V} / \mathrm{m}$.

Longer preceding interstroke intervals allow the lightning channel to cool down to a lower temperature so that its conductivity decreases to a lower value. As a result, channel conditions are less favorable for supporting a new dart leader and more charge is required to maintain the progression of the leader. More charge at the leader tip will result in a higher peak current and consequently higher peak electric field. Rakov et al. [3] report correlation coefficients of about 0.3 for the data analyzed by both Berger et al. [2] and Rakov et al. [4] when correlations were estimated based on individual field measurements as opposed to the mean values in this study.

\section{G. Flash Duration}

Berger et al. [2] reported for negative multiple-stroke flashes a median duration of $180 \mathrm{~ms}$ (see Table VIII).

Flash duration measured by ALDIS is defined as the duration between the onset time ( $t_{\mathrm{on}}$ in Fig. 2$)$ of the first stroke and the onset time of the last stroke of the flash. We limited the investigation to a maximum flash duration of $1 \mathrm{~s}$. The data set $(N=15905)$ is the same as that used in Section IV-C because for this analysis a located first stroke is also required. Although the sample size is much larger than that of Berger et al. [2] and the measuring technique is completely different from Berger et al. [2], the results are similar. Fig. 11 shows the frequency distribution of the flash duration. 


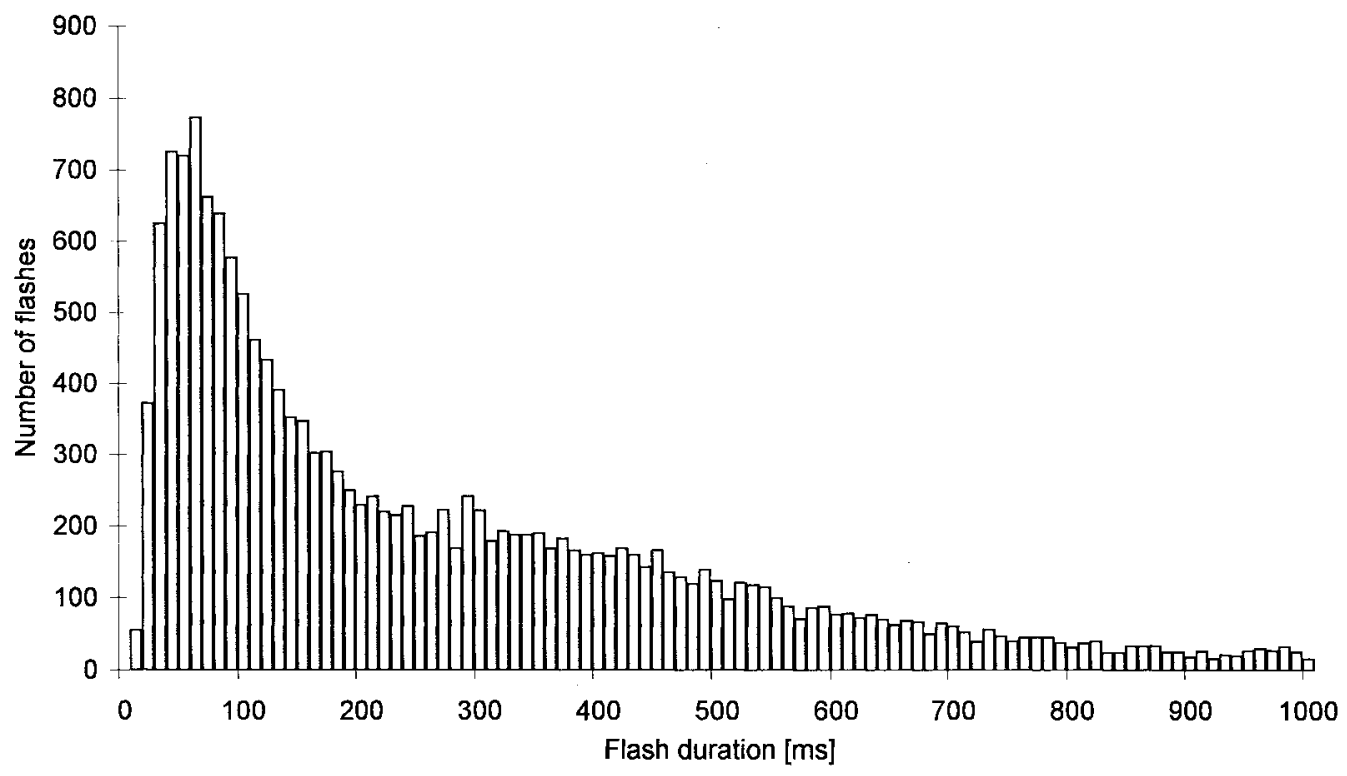

Fig. 11. Histogram of flash duration for the selected 1996 ALDIS data.

TABLE IX

MeAn Risetimes $T_{\text {rise }}$ RePorted by ALDIS

\begin{tabular}{l|c|c|c}
\cline { 2 - 3 } & $\mathrm{N}$ & $\begin{array}{c}\text { mean rise- } \\
\text { time } T_{\text {rise }}[\mu \mathrm{s}]\end{array}$ & $\begin{array}{c}\text { MASTER et al. } \\
(1984)\end{array}$ \\
\hline single-stroke flashes & 13640 & 8 & \multirow{2}{*}{4.4} \\
\hline first strokes in multiple-stroke flashes & 13115 & 8.9 & \\
\hline subsequent strokes & 9899 & 8.3 & 2.8 \\
\hline
\end{tabular}

\section{H. Risetime Versus Amplitude}

The risetime of the electromagnetic field waveform is reported by the IMPACT DF's to the central analyzer and it is the time between threshold crossing and the time of peak of the signal, ( $T_{r}$ in Fig. 2). Using (2) we can estimate the zero to peak risetime $T_{\text {rise }}$ of the lightning electromagnetic field pulse at the DF site.

Risetime of the electromagnetic pulse is affected by the finite ground conductivity of the propagation path from the flash location to the sensor site (e.g. Krider et al. [15]). To limit this effect to some extent, we have used for this investigation only data from the DF in the center station (Niederoeblarn) of the selected area (see Fig. 3) of the Austrian network. Thus, the propagation distance to the DF is always less than 100 $\mathrm{km}$. Note that in the following, stroke peak currents are the peak currents calculated as mean values for all the contributing DF's, applying the GAI calibration (see Table IV).

Master et al. [17] reported $4.4 \mu \mathrm{s}$ as mean of the zero to peak electric field risetime for 105 first strokes and a mean of $2.8 \mu \mathrm{s}$ for 220 subsequent strokes, all strokes being negative and occurring within $20 \mathrm{~km}$ or so in Florida.

We have evaluated a magnetic field risetime $T_{\text {rise }}$ of $8.0 \mu \mathrm{s}$ for the only strokes in single-stroke flashes, $8.9 \mu \mathrm{s}$ for first strokes in multiple-stroke flashes, and $8.3 \mu$ s for subsequent strokes, respectively. The results are summarized in Table IX.
It is interesting to note that there is little difference in the field risetimes of first and subsequent strokes in the ALDIS data. This could be due to the more pronounced propagation effects in our data compared to Florida measurements. In Figs. 12-14, we show the mean risetime versus peak field for the three different categories of strokes. For all three categories, we observe a similar increase of the mean risetime with increasing peak field. The increasing spread for higher peak fields in these figures is due to the limited number of measurements suitable for the calculation of the mean risetime. A decreasing gradient $\Delta T_{r} / \Delta E$ with increasing peak field indicates that higher peak fields are associated with higher rates of rise.

On the other hand, the observed dependency of risetime on peak electric field could also be partial or total by the result of propagation effects. With increasing propagation distance and decreasing ground conductivity, the risetime of the pulse will increase. This effect is, therefore, angle (determines the propagation path and its conductivity) and distance dependent. Separation of the above mentioned effects is not an easy task and outside of the scope of this paper.

\section{DISCUSSION}

The Austrian lightning locating system ALDIS is probably one of the today's best performing lightning locating systems 


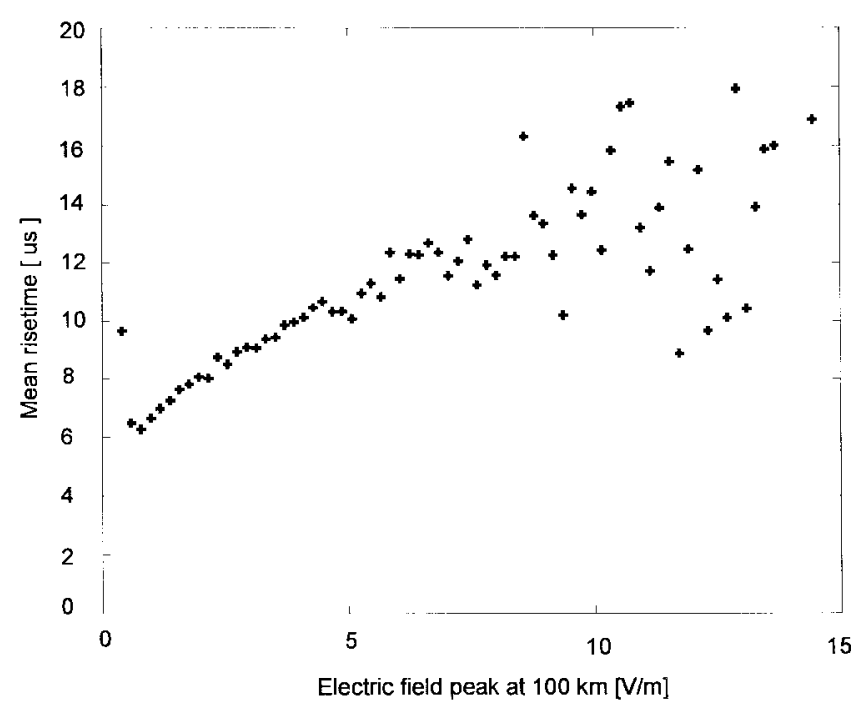

Fig. 12. Mean of the sensor (Niederoeblarn) reported risetime $T_{\text {rise }}$ versus peak field for single-stroke flashes and distances less than $100 \mathrm{~km}$.

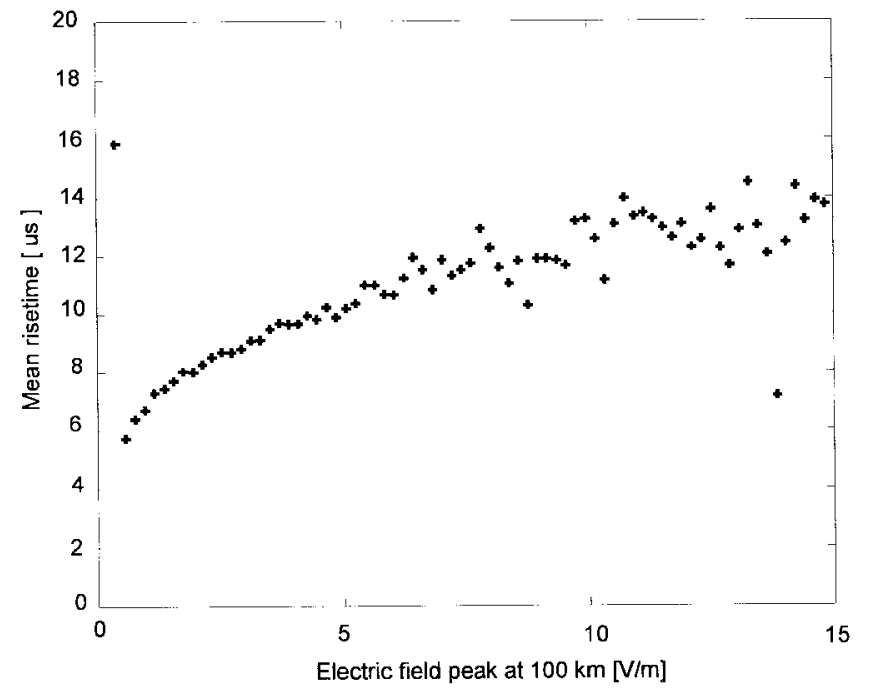

Fig. 13. Mean of the sensor (Niederoeblarn) reported risetime $T_{\text {rise }}$ versus peak field for first strokes in multistroke flashes and distances less than 100 $\mathrm{km}$.

all over the world (high gain and relatively small distances between the DF's). We selected for the present investigation an area with maximum detection efficiency estimated to be above 90\% (Schulz [25]). Besides the DE, the stroke grouping algorithm may have some influence on the resulting lightning parameters from ALDIS and lend to discrepancies between the lightning parameters from the locating system and those found in the literature.

Observed differences between lightning parameters estimated from the lightning locating system data and from field or tower measurements could be caused by one or a combination of the following reasons.

Possibly, first strokes in the Alpine region in Austria are different from first strokes in Florida, consistent with the hypothesis that lightning parameters are different in different topographic and climatic regions. Perhaps many negative

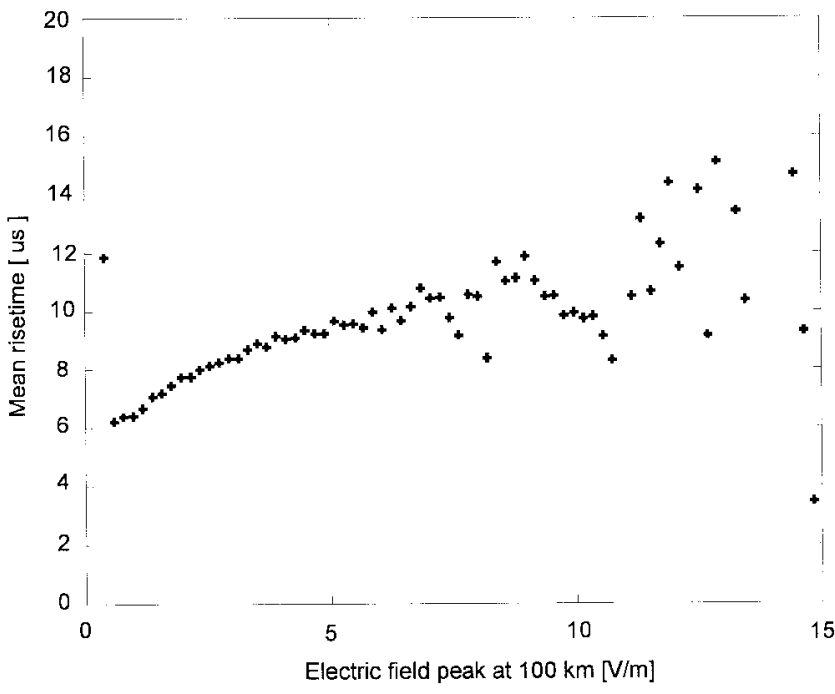

Fig. 14. Mean of the sensor (Niederoeblarn) reported risetime $T_{\text {rise }}$ versus peak field for subsequent strokes and distances less than $100 \mathrm{~km}$.

flashes in mountainous area are initiated by upward discharges. As a result, the high-current first stroke is missing and the locating system assigns a subsequent stroke as the first stroke (Rakov and Dulzon [19]).

Contrary to that, Thomson [27] showed that neither interstroke intervals nor the number of strokes per flash exhibits a significant dependence on latitude and also Cooray and Jayaratne [4] concluded that the characteristics of lightning ground flashes in different geographical regions are similar. On the other hand, several investigators reported that frontal and air-mass storms differ in terms of the average number of strokes per flash (e.g., Rakov and Dulzon [20]).

Further, measurements in previous studies usually included data from a limited number of thunderstorms. The ALDIS data are covering an entire year with all different types of thunderstorms and stages of storm development. We showed in this paper that the percentage of single-stroke flashes and the number of strokes per flash exhibit a considerable variability for the individual storms even in the same region. Statistical evaluations based on data for a few storms may, therefore, be not representative of the total lightning activity in a region. Thus, we conclude that it is very important to be aware of possible bias, when data from only a single storm are analyzed.

Data from Rakov et al. [24] are for lightning within $20 \mathrm{~km}$ in Florida, whereas the ALDIS data involve longer propagation distances (up to a few hundred kilometers) and generally lower ground conductivity.

Lightning peak fields of subsequent strokes measured by ALDIS are similar to measured lightning peak fields of subsequent strokes found in the literature.

One of the most interesting results of this study is that the ALDIS data do not show the usual 2:1 ratio between the median values of the field peaks of first and subsequent strokes. On the other hand, the spatial resolution of a location system does not allow to distinguish between subsequent strokes in the same channel and strokes creating a new channel (Rakov et al. [21]), as long as the separation of termination points is in the 
range of some hundreds of meters or less. If strokes creating new terminations on ground radiate higher initial field peaks (see Rakov and Uman [21]) and those strokes are identified as subsequent strokes by the locating system, this would increase the mean of initial field peaks for subsequent strokes and make this mean more similar to that for the first strokes.

The limited detection efficiency (which is partly due to propagation effects) results in biases in the percentage of single-stroke flashes toward higher values and in the number of strokes per flash toward lower values. The percentage of single-stroke flashes is in the range from 30 and $80 \%$ for different thunderstorm days. The number of strokes per flash for different thunderstorm days is in the range from 1.2 to 4.2 .

The interstroke intervals measured by ALDIS are similar to those measured by Rakov et al. [24]. This parameter is probably less dependent on DE because only located successive strokes (according to the APA) are used. The result that longer preceding interstroke intervals are related to larger stroke amplitudes should not be influenced by the DE at all.

The percentage of subsequent strokes having peaks greater than the first stroke peaks measured by ALDIS is higher than values reported in the literature. We cannot explain this difference by the limited DE because in this case the percentage detected by ALDIS should be smaller than the percentage found in literature. As already mentioned, the ALDIS data, in general, result in similar median values of the field peaks for first and subsequent strokes. In view of the first and subsequent strokes showing about the same peak values, it is suprising that the peak of one subsequent stroke in a flash often exceeds the first stroke peak.

The flash duration measured by ALDIS is similar to the flash duration measured by Berger et al. [2]. This parameter should not be influenced by DE because we only used flashes with a detected first stroke (according to ALDIS) and, in this case, it does not matter if one or more strokes occuring between the first and the last strokes is missing. It is only when either the first or the last (or both) stroke is missed the flash duration is determined incorrectly.

The majority of the analyzed parameters (median initial electric field peak for subsequent strokes, interstroke interval, flash duration) are in more or less good agreement with parameters independently measured by other techniques.

\section{REFERENCES}

[1] R. B. Anderson and A. J. Erikson, "Lightning parameters for engineering application," Electra, vol. 69, pp. 65-102, 1980.

[2] K. Berger, R. B. Anderson, and H. Kroeninger, "Parameters of lightning flashes," Electra, vol. 41, pp. 23-37, 1975.

[3] V. Cooray and H. Perez, "Some features of lightning flashes observed in Sweden," J. Geophys. Res., vol. 99, no. D5, pp. $10683-10$ 688, 1994.

[4] V. Cooray and K. P. S. C. Jayaratne, "Characteristics of lightning flashes observed in Sri Lanka in the tropics," J. Geophys. Res., vol. 99, no. D19, pp. 21 051-21 056, 1994.

[5] K. L. Cummins, E. A. Bardo, W. L. Hiscox, R. B. Pyle, A. E. Pifer, and E. P. Krider, "A combined TOA/MDF technology upgrade of the U.S. national lightning detection network," in 23rd Int. Conf. Lightning Protection (ICLP), Firenze, Italy, Sept. 1996, pp. 143-148.

[6] G. Diendorfer, F. Hofbauer, and A. Stimmer, "The Austrian lightning detection \& information system-ALDIS-Configuration, organization, and first results," in 21st Int. Conf. Lightning Protection (ICLP), Berlin, Germany, Sept. 1992, pp. 319-320.

[7] G. Diendorfer, W. Schulz, F. Hofbauer, and A. Stimmer, "Results of a performance analysis of the Austrian lightning location network ALDIS," in 22nd Int. Conf. Lightning Protection (ICLP), Budapest, Hungary, Sept. 1994, Rep. 16-04.

[8] R. J. Fisher, G. H. Schnetzer, R. Thottappillil, V. A. Rakov, M. A. Uman, and J. D. Goldberg, "Parameters of triggered-lightning flashes in Florida and Alabama," J. Geophys. Res., vol. 98, no. D12, pp. 22 887-22 902, 1993.

[9] V. P. Idone, A. B. Saljoughy, R. W. Henderson, P. K. Moore, and R. B Pyle, "A reexamination of the peak current calibration of the National Lightning Detection Network," J. Geophys. Res., vol. 98, no. D10, pp. $18323-18332,1993$

[10] M. Ishii and J. I. Hojo, "Statistics on fine structure of cloud to ground lightning field waveforms," J. Geophys. Res., vol. 94, no. D11, pp. $13267-13274,1989$.

[11] H. Johannsdottir, "Comparison of lightning location systems," Master's thesis, Tech. Univ. Denmark, Electric Power Eng. Dept., 1993.

[12] N. Kitagawa, M. Brook, and E. J. Workman, "Continuing currents in cloud to ground lightning discharges," J. Geophys. Res., vol. 64, p. 637-647, 1962

[13] E. P. Krider, R. C. Noggle, and M. A. Uman, "A gated wideband magnetic direction finder for lightning return strokes," J. Appl. Meteorol., vol. 15, pp. 301-306, 1976.

[14] E. P. Krider, R. C. Noggle, A. E. Pifer, and D. L. Vance, "Lightning direction finding systems for forest fire detection, Bull Amer. Meteorol. Soc., vol. 61, pp. 980-986, 1980.

[15] E. P. Krider, C. Leteinturier, and J. C. Willett, "Submicrosecond fields radiated during the onset of first return strokes in cloud-to-ground lightning," J. Geophys. Res., vol. 101, no. D1, pp. 1589-1597, 1996.

[16] M. Maier, W. Hadrian, D. M. Jordan, G. Diendorfer, and W. Schulz, "Lightning electromagnetic field measurements in Austria-First results," in 23rd Int. Conf. Lightning Protection (ICLP), Firenze, Italy, Sept. 1996, pp. 155-160.

[17] M. J. Master, M. A. Uman, W. Beasley, and M. Darveniza, "Lightning induced voltages on power lines: Experiment," IEEE Trans. Power Apparatus Syst., vol. PAS-103, pp. 2518-2529, Sept. 1984.

[18] R. E. Orville, R. A. Weisman, R. B. Pyle, R. W. Henderson, and R. E. Orville, Jr., "Cloud to ground lightning flash characteristics from June 1984 through May 1985," J. Geophys. Res., vol. 92, no. D5, pp. 5640-5644, 1987

[19] V. A. Rakov and A. A. Dulzon, "On dependence of lightning peak current distribution on height above sea level (in Russian)," Izv. VUZov SSSR-Energetika, vol. 4, pp. 24-28, 1986a.

[20] "Study of some features of frontal and convective thunderstorms (in Russian)," Meteorologiya i Gidrologiya, vol. 9, pp. 59-63, 1986b.

[21] V. A. Rakov and M. A. Uman, "Some properties of negative cloud-toground lightning flashes versus stroke order," J. Geophys. Res., vol. 95, no. D5, pp. 5447-5453, 1990

[22] V. A. Rakov, M. A. Uman, and R. Thottappillil, "On the empirical formula of Willett et al. relating lightning return stroke peak current and peak field," J. Geophys. Res., vol. 97, pp. 11527-11533, 1992a.

[23] V. A. Rakov, M. A. Uman, and D. V. Shelukhin, "On the possibility to improve an accuracy of the field amplitude lightning ranging technique (in Russian), Proc. Russian Academy of Sciences (ser. Radiotekhnika Elektronika), vol. 37, no. 2, pp. 237-239, 1992b.

[24] V. A. Rakov, M. A. Uman, and R. Thottappillil, "Review of lightning properties from electric field and TV observations," J Geophy. Res., vol. 99, no. D5, pp. 10745-10750, 1994

[25] W. Schulz, "Performance evaluation of lightning location systems," Ph.D. dissertation, Tech. Univ. Vienna, 1997.

[26] T. Soerensen, "Lightning registration systems analyzes, optimization and utilization," Ph.D. dissertation, Electric Power Eng. Dept., Tech. Univ. Denmark, 1995.

[27] E. M. Thomson, "The dependence of lightning return stroke characteristics on latitude," J. Geophys. Res., vol. 85, no. C2, pp. 1050-1056, 1980.

[28] R. Thottappillil, V. A. Rakov, M. A. Uman, W. H. Beasley, M. J. Master, and D. V. Shelukhin, "Lightning subsequent-stroke electric field peak greater than the first stroke peak and multiple ground terminations," $J$. Geophys. Res., vol. 97, no. D7, pp. 7503-7509, 1992.

[29] M. A. Uman, T. Lin, and E. P. Krider, "Errors in magnetic direction finding due to nonvertical lightning channels," Radio Sci., vol. 15, no. 1, pp. 35-39, 1980.

[30] J. C. Willett, J. C. Bailey, V. P. Idone, A. Eybert-Berard, and C. Barret, "Submicrosecond intercomparison of radiation fields and currents in triggered lightning return strokes based on the transmission-line model," J. Geophys. Res., vol. 94, pp. 13.275-13.286, 1989. 


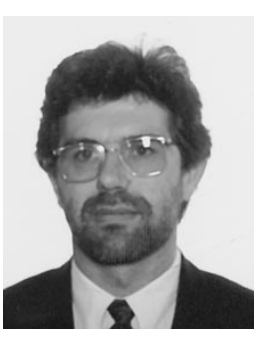

Gerhard Diendorfer was born in Haslach, Austria, on June 10, 1957. He received the Dipl.-Ing. degree (electrical engineering) and the Doctor of Technology degree from the Technical University, Vienna, Austria, in 1982 and 1987, respectively.

From 1982 to 1990, he was employed as an Assistant Professor at the Technical University of Vienna. He spent the academic year 1988-1989 at the Lightning Research Laboratory, University of Florida, Gainesville, working in return stroke modeling. Presently, he is heading the Austrian Lightning Detection and Information System (ALDIS).

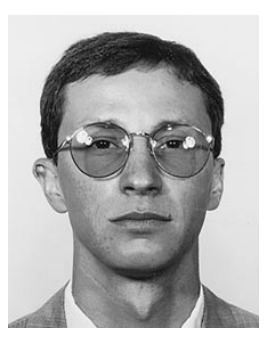

Wolfgang Schulz was born in Vienna, Austria, in 1966. He received the Dipl.-Ing. degree (electrical engineering) and the Doctor of Technology degree from the Technical University Vienna, Austria, in 1992 and 1997, respectively.

In 1992, he was employed as Assistant Professor at the Technical University of Vienna. Currently, he is employed at the Austrian Lightning Detection and Information System (ALDIS).

V. A. Rakov, for photograph and biography, see this issue p. 426 